\title{
STUDY OF URINARY NEUTROPHIL GELATINASE-ASSOCIATED LIPOCALIN (NGAL) IN PATIENTS WITH LIVER CIRRHOSIS AND ITS RELATION TO HEPATORENAL SYNDROME
}

\author{
Fathalla S. Ismail $^{(1)}$, Gamal El-Din A. Badr ${ }^{(2)}$, Marwa A. Madkour ${ }^{(2)}$, Salwa H. Gomaa ${ }^{(3)}$ \\ , Sara E. El-Sayed ${ }^{(2)}$ \\ ${ }^{I}$ Department of Internal Medicine; Faculty of Medicine, ${ }^{2}$ Department of Experimental and Clinical \\ Internal Medicine; Medical Research Institute, ${ }^{3}$ Department of Chemical Pathology; Medical Research \\ Institute; Alexandria University
}

Abstract:

Background: Hepatorenal syndrome (HRS) is a unique form of kidney injury resulting from renal vasoconstriction in the setting of systemic and splanchnic arterial vasodilatation in patients with advanced cirrhosis. Neutrophil gelatinase-associated lipocalin (NGAL) is a proved biomarker of acute and chronic renal injury.

Aim of the work was to study urinary NGAL level in patients with liver cirrhosis and its relation to HRS.

Subjects and methods: The study included 5 groups; group I (15 patients with cirrhosis, no ascites and normal renal function), group II (15 patients with cirrhosis, ascites and normal renal function), group III (15 patients with cirrhosis, ascites and HRS), group IV (15 patients with cirrhosis, ascites and chronic kidney disease; CKD) and group V (15 healthy subjects) as control group. The diagnosis of HRS was based on the International Ascites Club criteria. The glomerular filtration rate (GFR) was calculated using 2 formulas: The Chronic Kidney Disease Epidemiology Collaboration (CKD-EPI) and the Extended Modification of Diet in Renal Disease (Ext-MDRD) formula. Urinary level of neutrophil gelatinase lipocalin (NGAL) was done using ELISA, and neutrophil gelatinase associated lipocalin/ urinary creatinine concentration (NGAL/UCC) ratio was calculated.

Results: Both NGAL level and NGAL/UCC ratio increased significantly in cirrhotic patient with HRS, while only NGAL/UCC ratio significantly increased in cirrhotics with CKD compared to normal controls and to cirrhotics with normal serum creatinine. NGAL level and NGAL/UCC ratio were higher in HRS compared to CKD cirrhotics, they could successfully identify HRS at cut-off values of $100 \mathrm{ng} / \mathrm{ml}$ and 0.9 , respectively. Both markers correlated with each other and with blood urea, serum creatinine, estimated GFR, and Child-Pugh score of patients. Conclusion: Urinary NGAL level and NGAL/UCC ratio can be used as markers for early detection of HRS among patients with cirrhosis. However, the elevation of NGAL in the setting of HRS confirms the speculation that HRS entails a degree of structural kidney injury rather than being purely functional. Larger studies with higher number of patients are needed to investigate the value of urinary NGAL in type I and type II HRS separately, and to examine the role of other markers for early detection of HRS to improve its prognosis.

Key Words: Hepatorenal syndrome: HRS, Neutrophil gelatinase-associated lipocalin: NGAL, chronic kidney disease: CKD, the Chronic Kidney Disease Epidemiology Collaboration: CKD-EPI, the Extended Modification of Diet in Renal Disease: Ext-MDRD, neutrophil gelatinase associated lipocalin/ urinary creatinine concentration: NGAL/UCC

\section{INTRODUCTION}

$\mathbf{R}$ enal dysfunction is a common complication in patients with endstage liver cirrhosis. Hepatorenal syndrome (HRS) is a unique form of kidney injury resulting from renal vasoconstriction in the setting of systemic and splanchnic arterial vasodilatation in patients with advanced cirrhosis. ${ }^{(1)}$ HRS is typically subdivided into two types. In type-I HRS, there is a rapid deterioration in kidney function with the serum creatinine increasing by more than $100 \%$ from baseline to greater than $2.5 \mathrm{mg} / \mathrm{dl}$ within a twoweeks period. On the other hand, HRS type II usually occurs in patients with refractory ascites and slowly progresses over a period of weeks to months. ${ }^{(2)}$ HRS is defined as the presence of ascites, serum creatinine $>1.5 \mathrm{mg} / \mathrm{dl}$, no infection $\left(\mathrm{WBC}<11000 / \mathrm{mm}^{3}\right.$ ), proteinuria< $500 \mathrm{mg} / \mathrm{dl}$ and no other explanation for kidney failure such as diabetes or atherosclerotic disease. ${ }^{(3)}$ In patients with advanced cirrhosis, HRS is reported to occur in $18 \%$ within one year of diagnosis and up to $40 \%$ at five years. ${ }^{(4)}$ If left untreated, the median survival is two weeks for patients with type-I HRS and four to six months in patients with type-II HRS. ${ }^{(5)}$ 
Neutrophil gelatinase-associated lipocalin (NGAL), also known as Lipocalin-2 (LCN2) is a protein that in human is encoded by the Lipocalin-2 (LCN2) gene. ${ }^{(6-8)}$ It is naturally expressed in neutrophils and at low levels in the kidney, prostate, and epithelia of the respiratory and alimentary tracts. ${ }^{(7,9)} \mathrm{NGAL}$ is involved in the natural innate immunity and it has been found to function as a growth factor and differentiation factor in multiple cell types, including developing and mature renal epithelia. ${ }^{(10)}$ Many studies proved the role of NGAL as a biomarker of renal injury. ${ }^{(11,12)}$ In acute kidney injury (AKI), NGAL was detected at high levels in blood and urine within 2 hours of injury. ${ }^{(11)}$ Because NGAL molecule is protease resistant and small in size, the protein is easily excreted and detected in urine. ${ }^{(13)}$ NGAL levels in patients with AKI have been associated with the severity of their prognosis and hence can be used as a biomarker for AKI. (11) It can also be used for early diagnosis of chronic kidney disease as well as conditions like contrast induced nephropathy, transplant kidney rejection and hepatorenal syndrome. ${ }^{(14-16)}$

Classically, kidney health status has been mostly measured by serum creatinine. However, NGAL level has been found to be a more precise, sensitive and early marker for diagnosing acute and chronic kidney disease than serum creatinine levels. Therefore, monitoring NGAL levels may reduce delayed diagnosis and treatment of acute and chronic kidney disease, and hence reduces morbidity and mortality. ${ }^{(17)}$ So far, only few studies have attempted to investigate the role of NGAL in diagnosis of hepatorenal syndrome in cases of liver cirrhosis. ${ }^{(16)}$ Therefore, the aim of this work was to study urinary NGAL level in patients with liver cirrhosis and its relation to HRS.

\section{SUBJECTS AND METHODS:}

This study was done after the approval of Ethical committee of Medical Research Institute, Alexandria University and it included 5 groups: group I included 15 patients with liver cirrhosis but with no ascites or impaired renal function, group II included 15 patients with liver cirrhosis and ascites, but with no renal impairment, group III included 15 patients with liver cirrhosis, ascites and HRS, group IV included 15 patients with liver cirrhosis and ascites associated with impaired renal function due to chronic kidney disease (CKD) and group $\mathrm{V}$ included 15 age and sex-matched healthy subjects with no evidence of liver or renal diseases as control group. The diagnosis of cirrhosis was made on basis of clinical examination, laboratory investigations and abdominal ultrasonography. ${ }^{(18,19)}$ The diagnosis of HRS was made on basis of criteria for diagnosis of HRS set by the International Ascites Club. ${ }^{(20)}$ Patients with causes of ascites other than portal hypertension were excluded from the study, e.g. congestive heart failure and abdominal malignancy. ${ }^{(21)}$ Also, patients with evidence of urinary tract infection or active spontaneous bacterial peritonitis were excluded due to their potential effect on
NGAL level. ${ }^{(22-24)}$ Informed written consent will be taken from all subjects enrolled in the study. All patients were recruited from Medical Research Institute, Alexandria University.

All patients were subjected to detailed history taking and physical examination. They were scored according to Child-Pugh classification. ${ }^{(25,26)}$ Plain X-ray chest and echocardiogram were done to exclude pulmonary or cardiac disorders. Abdominal ultrasound examination was done to confirm the diagnosis of liver cirrhosis, and to assess organic causes of renal disease. The ultrasound grade of chronic renal prenchymal disease was scored as follows: ${ }^{(27)}$ grade 0: normal; renal cortex is slightly less echogenic than the liver or spleen, grade I: renal cortex is of the same echogenicity like liver or spleen, grade II: renal cortex is mildly to moderately more echogenic than liver or spleen, with some loss of corticomedullary distinction, and grade III: renal cortex is severely echogenic obliterating the highly echogenic renal sinus.

Routine Laboratory investigations (using the Olympus AU400 clinical chemistry analyzer) included liver function profile, fasting blood sugar, renal function tests, serum electrolytes and serum uric acid. ${ }^{(28)}$ Complete urine analysis and urinary albumin to creatinine ratio were performed. ${ }^{(28)}$ Complete blood count was done using Sysmex X 1800 I ${ }^{\left({ }^{(2)}\right.}$ Viral markers (hepatitis C antibody and hepatitis B surface antigen) were also performed using the enzyme-linked immunosorbent assay (ELISA) technique. $^{(28)}$ The glomerular filtration rate (GFR) was calculated using 2 formulas. The Chronic Kidney Disease Epidemiology Collaboration (CKD-EPI) ${ }^{(30)}$ equation was as follows: GFR $=141 \times \min \left(\mathrm{S}_{\mathrm{cr}} / \kappa, 1\right)^{\alpha} \times \max \left(\mathrm{S}_{\mathrm{cr}} / \kappa, 1\right)^{-}$ $1.209 \times 0.993^{\text {Age }} \times 1.018$ [if female] $\times 1.159$ [if black]. The Extended Modification of Diet in Renal Disease (ExtMDRD) ${ }^{(31)}$ 6-variable equation was as follows: GFR = $170 \times$ (serum creatinine $\mathrm{mg} / \mathrm{dL})^{-0.999} \mathrm{x}(\text { age })^{-0.176} \times(0.762$ if female) $\mathrm{x}$ (1.180 if of African descent) $\mathrm{x}$ (urea nitrogen $\mathrm{mg} / \mathrm{dL}){ }^{-0.170} \mathrm{x}$ (albumin g/dL) ${ }^{+0.318}$. Kidney Disease Improving Global Outcomes (KDIGO-2013) (32) staging system was used for staging CKD patients as follows: G1: > $90 \mathrm{ml} / \mathrm{min} / \mathrm{m}^{2}, \mathrm{G} 2: 60-89 \mathrm{ml} / \mathrm{min} / \mathrm{m}^{2}$, G3a: $45-59$ $\mathrm{ml} / \mathrm{min} / \mathrm{m}^{2}$, G3b: $30-44 \mathrm{ml} / \mathrm{min} / \mathrm{m}^{2}, \mathrm{G} 4: 15-29 \mathrm{ml} / \mathrm{min} / \mathrm{m}^{2}$ and $\mathrm{G} 5:<15 \mathrm{ml} / \mathrm{min} / \mathrm{m}^{2}$.

Measurement of urinary level of neutrophil gelatinaseassociated lipocalin (NGAL) was done for all patients using ELISA kit provided by Cusabio Company, China, ${ }^{(33)}$ and neutrophil gelatinase associated lipocalin/ urinary creatinine concentration (NGAL/UCC) ratio was calculated for all subjects.

\section{STATISTICAL ANALYSIS:}

Statistical Package for Social Sciences software (SPSS, Windows version release 18.0; SPSS Inc.; Chicago, IL, USA) was used for analyzing data. Qualitative data were analyzed using number, percent and Chi-square test. When more than $20 \%$ of the cells had expected count less than 5 , correction for Chi-square was conducted using 
Monte Carlo correction. Normally distributed quantitative data were expressed in mean and standard deviation (Mean. \pm SD) and compared using $\mathrm{F}$ test (ANOVA), while abnormally distributed quantitative data were expressed in Median (Min. - Max.) and compared using Kruskal Wallis test. Paired t-test was used to analyze paired data. Correlations between two quantitative variables were assessed using Spearman coefficient. Significance test results were quoted as two-tailed probabilities. Significance of the obtained results was judged at the $5 \%$ level. ${ }^{(34,35)}$

\section{RESULTS}

\section{Demographic, clinical and ultrasound data:}

The males were more predominant, representing $66.7 \%$ of groups I, II, III and V and $73.3 \%$ of group IV, and rural residence represented $66.7 \%$ of all groups. The age range was between 36.0 and 69.0 years, with no statistically significant difference between groups as regards sex, residence or age. The mean arterial blood pressure ranged between 70.0 and $120.0 \mathrm{~mm} \mathrm{Hg}$ in all groups, being highest in group IV and lowest in group III $(p<0.001)$. Clinically; jaundice, palmar erythema, splenomegaly, ascites and lower limb edema were among the highest reported findings. By ultrasound examination, ascites was absent in all patients of groups I and V, while other groups had variable grades of ascites, as demonstrated in table (1). The ultrasound grade of parenchymal kidney disease was scored zero (normal) in all patients of groups I,II, III and V. In group IV, $33.3 \%$ of patients had grade 0 , $40.0 \%$ had grade $1,26.7 \%$ had grade 2 and no patients had grade 3 CKD.

\section{Hematologic and liver profile data:}

The mean values for hemoglobin concentration and red blood cells count (RBCs) were significantly different between the groups being lowest in group IV, the platelets count was lowest in group II, while the international normalized ratio (INR) was highest in group III. Serum albumin was lowest in groups II and III, while serum bilirubin was highest in group III. The Child-Pugh score was significantly different between groups $(\mathrm{p}<0.001)$ being highest in groups II and III, as demonstrated in table (2).

All subjects of group I were Child class A liver cirrhosis, $80 \%$ of group II and III were Child class C and the remaining $20 \%$ were Child class B. In group IV Child class A represented $13.3 \%$ of patients, while $26.7 \%$ and $60.0 \%$ were Child class B and Child class C, respectively. Hepatitis $\mathrm{C}$ virus (HCV) was the main etiology for liver cirrhosis in all groups. Only one patient in group II had autoimmune liver cirrhosis, one patient in group III was hepatitis B positive and another one in group IV had cardiac cirrhosis.

Renal and glycemic profile data:

Fasting serum glucose was significantly different between patient groups (I-IV), ranging between 73.0 and 353.0 $\mathrm{mg} / \mathrm{dl}$ and being highest in group IV. Blood urea and serum creatinine were significantly higher in groups III and IV, while serum uric acid was highest in group IV. Serum calcium was significantly lower in group IV, and serum sodium was lowest in group III, whereas serum phosphorus and potassium were comparable between all groups, as demonstrated in table (3).

Table (1): Demographic, clinical and ultrasound data in the studied groups.

\begin{tabular}{|c|c|c|c|c|c|c|}
\hline & $\begin{array}{l}\text { Group I } \\
(\mathbf{n}=\mathbf{1 5})\end{array}$ & $\begin{array}{c}\text { Group II } \\
(\mathbf{n}=\mathbf{1 5})\end{array}$ & $\begin{array}{c}\text { Group III } \\
(\mathbf{n}=\mathbf{1 5})\end{array}$ & $\begin{array}{c}\text { Group IV } \\
(\mathbf{n}=15)\end{array}$ & $\begin{array}{c}\text { Group V(Control) } \\
(\mathbf{n}=\mathbf{1 5})\end{array}$ & $\mathbf{P}$ \\
\hline Age $($ years) $($ Mean \pm SD) & $54.27 \pm 4.79$ & $57.60 \pm 9.72$ & $53.33 \pm 8.50$ & $55.87 \pm 6.41$ & $52.60 \pm 5.84$ & 0.341 \\
\hline $\begin{array}{l}\text { Mean BP }(\mathbf{m m H g}) \\
(\text { Mean } \pm \text { SD })\end{array}$ & $88.33 \pm 9.57$ & $84.8 \pm 11.56$ & $79.7 \pm 10.03$ & $98.4 \pm 12.59$ & $91.33 \pm 6.76$ & $<0.001^{*}$ \\
\hline Jaundice n, (\%) & $0(0.0 \%)$ & $8(53.3 \%)$ & $9(60.0 \%)$ & $5(33.3 \%)$ & - & $<0.001^{*}$ \\
\hline $\begin{array}{l}\text { Bleeding tendency } \\
\mathrm{n},(\%)\end{array}$ & $4(26.7 \%)$ & $5(33.3 \%)$ & $7(46.7 \%)$ & $5(33.3 \%)$ & - & 0.707 \\
\hline Palmar erythema n, $(\%)$ & $7(46.7 \%)$ & $8(53.3 \%)$ & $10(66.7 \%)$ & $12(80.0 \%)$ & - & 0.292 \\
\hline $\begin{array}{l}\text { Disturbed consciousness } n \text {, } \\
(\%)\end{array}$ & $0(0.0 \%)$ & $0(0.0 \%)$ & $2(13.3 \%)$ & $1(6.7 \%)$ & - & 0.608 \\
\hline Flappy tremors $\mathrm{n},(\%)$ & $0(0.0 \%)$ & $3(20.0 \%)$ & $7(46.7 \%)$ & $6(40.0 \%)$ & - & $0.011^{*}$ \\
\hline $\begin{array}{l}\text { Abdominal tenderness } \mathrm{n} \text {, } \\
(\%)\end{array}$ & $0(0.0 \%)$ & $2(13.3 \%)$ & $4(26.7 \%)$ & $2(13.3 \%)$ & - & 0.234 \\
\hline Hepatomegaly $n,(\%)$ & $0(0.0 \%)$ & $3(20.0 \%)$ & $4(26.7 \%)$ & $7(46.7 \%)$ & - & $0.018^{*}$ \\
\hline Splenomegaly n, (\%) & $0(0.0 \%)$ & $8(53.3 \%)$ & $10(66.7 \%)$ & $9(60.0 \%)$ & - & $0.001^{*}$ \\
\hline Ascites n, (\%) & $0(0.0 \%)$ & $15(100.0 \%)$ & $15(100.0 \%)$ & $14(93.3 \%)$ & - & $<0.001^{*}$ \\
\hline $\begin{array}{l}\text { Lower Limb edema } \\
\mathrm{n},(\%)\end{array}$ & $1(6.7 \%)$ & $15(100.0 \%)$ & $14(93.3 \%)$ & $14(93.3 \%)$ & - & $<0.001^{*}$ \\
\hline Grade of ascites & $0.0 \pm 0.0$ & $2.47 \pm 0.52$ & $2.40 \pm 0.51$ & $2.13 \pm 0.83$ & - & $<0.001^{*}$ \\
\hline $0 \mathrm{n},(\%)$ & $15(100.0 \%)$ & $0(0.0 \%)$ & $0(0.0 \%)$ & $0(0.0 \%)$ & $0(0.0 \%)$ & $<0.001^{*}$ \\
\hline $1 \mathrm{n},(\%)$ & $0(0.0 \%)$ & $0(0.0 \%)$ & $0(0.0 \%)$ & $4(26.7 \%)$ & $0(0.0 \%)$ & \\
\hline $2 \mathrm{n},(\%)$ & $0(0.0 \%)$ & $8(53.3 \%)$ & $9(60.0 \%)$ & $5(33.3 \%)$ & $0(0.0 \%)$ & \\
\hline $3 \mathrm{n},(\%)$ & $0(0.0 \%)$ & $7(46.7 \%)$ & $6(40.0 \%)$ & $6(40.0 \%)$ & $0(0.0 \%)$ & \\
\hline
\end{tabular}

F test (ANOVA), Sig. bet. Grps was done using Post Hoc test (Tukey), *: Statistically significant at $\mathrm{p} \leq 0.05$. 
Table (2): Hematologic and liver profile data in the studied groups.

\begin{tabular}{|c|c|c|c|c|c|c|}
\hline & $\begin{array}{l}\text { Group I } \\
(\mathbf{n}=\mathbf{1 5})\end{array}$ & $\begin{array}{l}\text { Group II } \\
(\mathbf{n}=\mathbf{1 5})\end{array}$ & $\begin{array}{c}\text { Group III } \\
(\mathbf{n}=\mathbf{1 5})\end{array}$ & $\begin{array}{c}\text { Group IV } \\
(\mathbf{n}=\mathbf{1 5})\end{array}$ & $\begin{array}{c}\text { Group V(Control) } \\
(\mathbf{n}=\mathbf{1 5})\end{array}$ & $\mathbf{P}$ \\
\hline Hb (g/dl) (Mean \pm SD) & $13.23 \pm 2.32$ & $10.67 \pm 1.21$ & $10.30 \pm 1.54$ & $9.72 \pm 1.06$ & $13.61 \pm 1.48$ & $<0.001^{*}$ \\
\hline RBCs $($ Mean \pm SD) & $4.80 \pm 1.22$ & $3.69 \pm 0.67$ & $3.61 \pm 0.88$ & $3.29 \pm 0.52$ & $5.31 \pm 0.73$ & $<0.001^{*}$ \\
\hline WBC $($ Mean \pm SD) & $6.26 \pm 2.20$ & $4.84 \pm 2.09$ & $5.42 \pm 2.26$ & $6.63 \pm 2.72$ & $6.86 \pm 1.58$ & 0.073 \\
\hline Platelets (Mean \pm SD) & $165.5 \pm 54.7$ & $112.9 \pm 55.6$ & $125.8 \pm 68.2$ & $165.9 \pm 79.4$ & $249 \pm 67.5$ & $<0.001^{*}$ \\
\hline INR $($ Mean \pm SD) & $1.18 \pm 0.11$ & $1.41 \pm 0.21$ & $1.48 \pm 0.32$ & $1.32 \pm 0.44$ & $1.01 \pm 0.03$ & $<0.001^{*}$ \\
\hline $\begin{array}{l}\mathbf{A S T}(\mathbf{I U} / \mathbf{L}) \\
\text { median(range) }\end{array}$ & $28(1-260)$ & $62(23-250)$ & $50(23-597)$ & $62(14-169)$ & $18(5-36)$ & $<0.001^{*}$ \\
\hline $\begin{array}{l}\text { ALT (IU/L) } \\
\text { median(range) }\end{array}$ & $32(6-128)$ & $37(10-131)$ & $23(9-299)$ & $29(10-163)$ & $16.0(8-40)$ & 0.060 \\
\hline $\begin{array}{l}\mathbf{A L P}(\mathbf{I U} / \mathbf{L}) \\
(\mathrm{Mean} \pm \mathrm{SD})\end{array}$ & $87.67 \pm 29.74$ & $112.5 \pm 40.98$ & $137.8 \pm 75.05$ & $144.9 \pm 78.50$ & $83.33 \pm 34.38$ & $0.007^{*}$ \\
\hline $\begin{array}{l}\text { GGT (IU/L) } \\
\text { median(range) }\end{array}$ & $50(16-168)$ & $47(13-95)$ & $38(8-404)$ & $62.5(14-475)$ & $27(8-45)$ & $0.024^{*}$ \\
\hline $\begin{array}{l}\text { Serum albumin }(\mathbf{g} / \mathbf{d l}) \\
(\text { Mean } \pm \mathrm{SD})\end{array}$ & $3.89 \pm 0.51$ & $2.33 \pm 0.23$ & $2.33 \pm 0.33$ & $2.43 \pm 0.64$ & $4.39 \pm 0.35$ & $<0.001^{*}$ \\
\hline $\begin{array}{l}\text { Total bilirubin }(\mathbf{m g} / \mathbf{d l}) \\
(\text { Mean } \pm \text { SD) }\end{array}$ & $0.89 \pm 0.39$ & $2.23 \pm 0.87$ & $4.77 \pm 2.51$ & $2.08 \pm 2.62$ & $0.56 \pm 0.25$ & $<0.001^{*}$ \\
\hline $\begin{array}{l}\text { Child-Pugh score } \\
\text { (Mean } \pm \text { SD) }\end{array}$ & $5.27 \pm 0.46$ & $10.60 \pm 1.50$ & $11.13 \pm 1.96$ & $9.33 \pm 1.72$ & - & $<0.001^{*}$ \\
\hline
\end{tabular}

Table (3): $\quad$ Comparison between groups according to renal and glycemic profile data.

\begin{tabular}{lcccccc}
\hline & $\begin{array}{c}\text { Group I } \\
(\mathbf{n}=\mathbf{1 5})\end{array}$ & $\begin{array}{c}\text { Group II } \\
(\mathbf{n}=\mathbf{1 5})\end{array}$ & $\begin{array}{c}\text { Group III } \\
(\mathbf{n}=\mathbf{1 5})\end{array}$ & $\begin{array}{c}\text { Group IV } \\
(\mathbf{n}=\mathbf{1 5})\end{array}$ & $\begin{array}{c}\text { Group V (Control) } \\
(\mathbf{n}=\mathbf{1 5})\end{array}$ & p \\
\hline FSG (mg/dl) & $94(81-221)$ & $90(73-303)$ & $97(53-307)$ & $157(74-353)$ & $87(75-106)$ & $0.006^{*}$ \\
\hline $\begin{array}{l}\text { Serum urea } \\
(\mathbf{m g} / \mathbf{d l})\end{array}$ & $28(18-40)$ & $27(15-40)$ & $106(48-251)$ & $149(37-234)$ & $28(17-40)$ & $<0.001^{*}$ \\
\hline $\begin{array}{l}\text { Serum creatinine } \\
(\mathbf{m g} / \mathbf{d l})\end{array}$ & $0.79 \pm 0.15$ & $0.79 \pm 0.16$ & $2.55 \pm 1.24$ & $2.68 \pm 0.81$ & $0.81 \pm 0.13$ & $<0.001^{*}$ \\
\hline $\mathbf{U A}(\mathbf{m g} / \mathbf{d l})$ & $4.81 \pm 0.81$ & $4.95 \pm 2.38$ & $9.29 \pm 2.99$ & $9.44 \pm 2.51$ & $4.58 \pm 0.98$ & $<0.001^{*}$ \\
\hline $\mathbf{C a}(\mathbf{m g} / \mathbf{d l})$ & $9.30 \pm 0.79$ & $8.10 \pm 0.55$ & $8.15 \pm 0.49$ & $7.99 \pm 0.61$ & $9.67 \pm 0.55$ & $<0.001^{*}$ \\
\hline $\mathbf{P}(\mathbf{m g} / \mathbf{d l})$ & $3.5(2.8-4.40)$ & $3.3(2.6-6.20)$ & $3.8(2.50-5.90)$ & $4.2(2.30-5.60)$ & $3.4(1.30-4.50)$ & 0.069 \\
\hline $\mathbf{N a}(\mathbf{m E q} / \mathbf{L})$ & $138.73 \pm 2.19$ & $135.47 \pm 6.33$ & $130.0 \pm 7.75$ & $134.33 \pm 6.60$ & $139.40 \pm 2.03$ & $<0.001^{*}$ \\
\hline $\mathbf{K}$ (mEq/L) & $4.44 \pm 0.43$ & $4.13 \pm 0.43$ & $4.67 \pm 1.04$ & $4.41 \pm 0.47$ & $4.41 \pm 0.45$ & 0.222 \\
\hline
\end{tabular}

*: Statistically significant at $\mathrm{p} \leq 0.05$. FSG: fasting serum glucose, UA: uric acid, Ca: calcium, P: phosphorus, Na: sodium, K: potassium, Sig. bet. Grps: significance between groups.

The etiology of CKD in group IV was predominantly diabetic nephropathy, representing $73.33 \%$ of patients. The remaining percent were due to lupus nephritis and type II mixed cryoglobinemia. The type of HRS in group III was predominantly type I, representing $80 \%$ of patients. The estimated GFR values using CKD-EPI and Ext-MDRD formulas were significantly lower in groups III and IV, as illustrated in figure (1). As regards KDIGO stage of CKD (based on CKD-EPI estimated GFR) in group IV, $6.7 \%$ were stage $3 \mathrm{~A}, 33.3 \%$ were stage $3 \mathrm{~B}$ and $60.0 \%$ were stage 4 .

\section{Urinary NGAL level and NGAL/UCC ratio:}

The mean values of urinary NGAL concentration and NGAL/UCC ratio were significantly different between groups $(p<0.001)$ being highest in group III. However, there was no significant difference between urinary NGAL levels of groups I and II compared to normal 
control (group V, $\mathrm{p}_{\text {cont }}>0.05$ ). There was a significant difference between urinary NGAL levels of groups III and IV compared to normal control (group V) and there was a significant difference of urinary NGAL levels between groups III and IV (p6<0.001). Regarding NGAL/UCC ratio; there was no significant difference between NGAL/UCC ratio of groups I and II compared to normal control (group $\mathrm{V}, \mathrm{p}_{\text {cont }}>0.05$ ), while there was a significant difference of groups III and IV compared to control group $\left(\mathrm{p}_{\text {cont }}<0.001\right)$, as well as a significant difference between groups III and IV $\left(\mathrm{p}_{6}<0.001\right)$, as presented in table (4).

There was a significant positive correlation between urinary NGAL concentration and NGAL/UCC ratio in all groups including control group (group V) $(\mathrm{p}<0.001)$. Significant positive correlations of urinary NGAL level and NGAL/UCC ratio were also found with serum urea, serum creatinine and Child score, while significant negative correlations were found with CKD-EPI and ExtMDRD estimated values of GFR, as shown in table (5).

The Receiver Operating Characteristic (ROC) curve analysis was used to evaluate the diagnostic performance of NGAL and NGAL/UCC ratio in identifying HRS. At a cut-off value of $100 \mathrm{ng} / \mathrm{ml}$, urinary NGAL showed a sensitivity of $93.33 \%$ and specificity of $64.44 \%$. the urinary NGAL/UCC ratio at a cut-off value of 0.9 , showed a sensitivity of $60.0 \%$ and a specificity of $93.33 \%$ in diagnosing HRS, as shown in table (6) and figures $(2,3)$

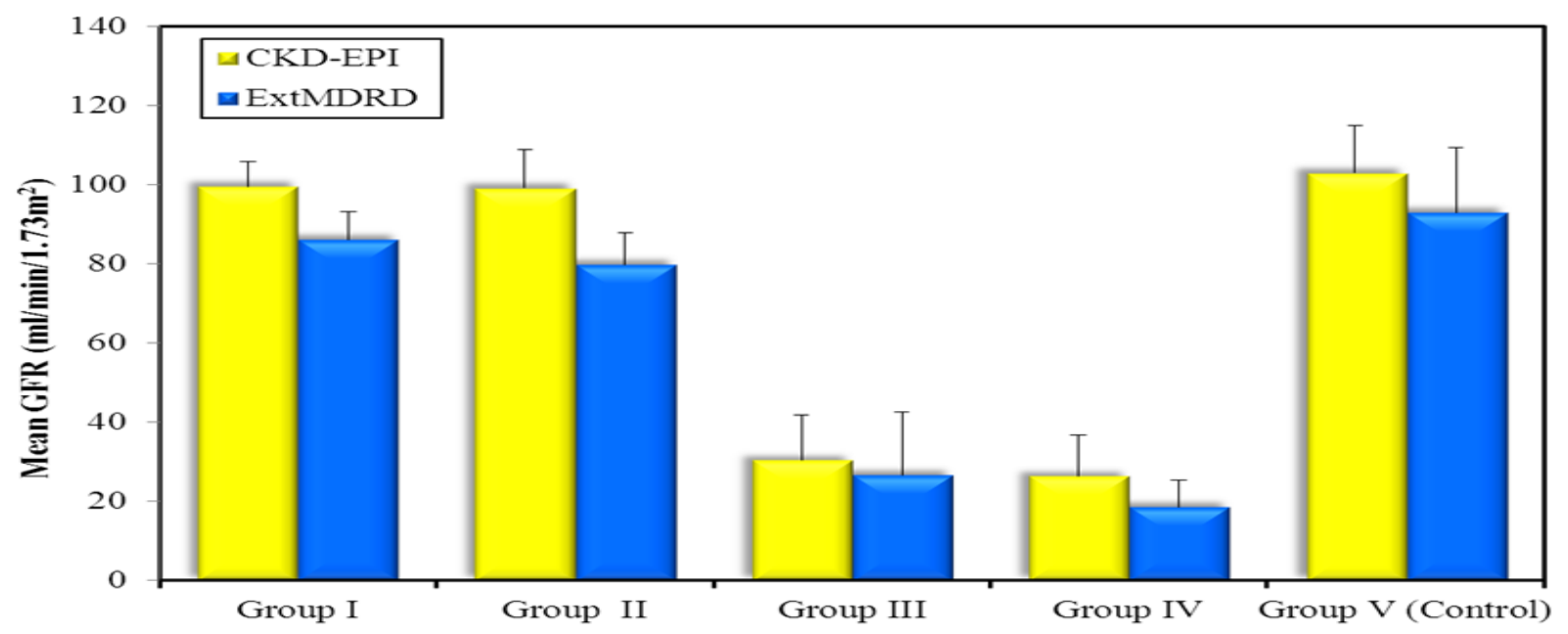

Figure (1): $\quad$ Estimated GFR by CKD-EPI and Ext-MDRD formulas in the studied groups.

Table (4): NGAL and NGAL/UCC ratio in the studied groups.

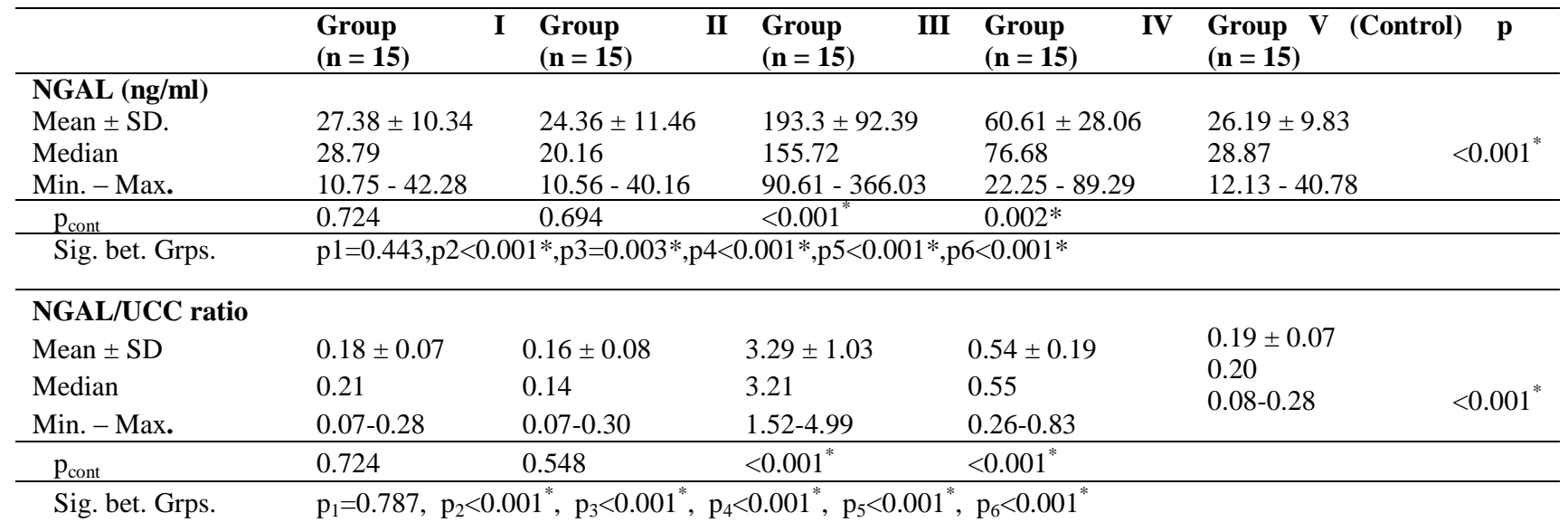

$\mathrm{p}_{\text {cont }}: \mathrm{p}$ value for comparing between control and each other group, $\mathrm{p}_{1}: \mathrm{p}$ value for comparing between group I and group II, $\mathrm{p}_{2}$ : $\mathrm{p}$ value for comparing between group I and group III, $\mathrm{p}_{3}$ : $\mathrm{p}$ value for comparing between group I and group $\mathrm{IV}, \mathrm{p}_{4}$ : $\mathrm{p}$ value for comparing between group II and group III, $\mathrm{p}_{5}: \mathrm{p}$ value for comparing between group II and group IV, $\mathrm{p}_{6}: \mathrm{p}$ value for comparing between group III and group IV, *: Statistically significant at $\mathrm{p} \leq 0.05$. NGAL: neutrophil gelatinase associated lipocalin, NGAL/UCC: neutrophil gelatinase associated lipocalin/ urinary creatinine, Sig. bet. Grps: significance between groups. 
Table (5): The significant correlations between NGAL and NGAL/UCC ratio with other parameters in the total sample.

\begin{tabular}{lllll}
\hline & NGAL & \multicolumn{2}{c}{ NGAL/UCC ratio } \\
\hline & $\mathbf{r}_{\mathrm{s}}$ & $\mathbf{p}$ & $\mathbf{p}$ & $\mathbf{r}_{\mathrm{s}}$ \\
Serum urea & $0.747^{*}$ & $<0.001^{*}$ & $0.803^{*}$ & $<0.001^{*}$ \\
Serum creatinine & $0.859^{*}$ & $<0.001^{*}$ & $0.892^{*}$ & $<0.001^{*}$ \\
CKD-EPI & $-0.741^{*}$ & $<0.001^{*}$ & $-0.784^{*}$ & $<0.001^{*}$ \\
Ext-MDRD & $-0.713^{*}$ & $<0.001^{*}$ & $-0.768^{*}$ & $<0.001^{*}$ \\
Child score & $0.333^{*}$ & $0.009^{*}$ & $0.401^{*}$ & $0.002^{*}$ \\
\hline
\end{tabular}

$\mathrm{r}_{\mathrm{s}}$ : Spearman coefficient $*$ : Statistically significant at $\mathrm{p} \leq 0.05$, CKD-EPI: Chronic Kidney Disease Epidemiology Collaboration formula, Ext-MDRD: Extended Modification of Diet in Renal Disease formula

Table (6): Agreement (sensitivity, specificity and accuracy) for urinary NGAL concentration and urinary NGAL/UCC ratio to diagnose HRS.

\begin{tabular}{lccc}
\hline & PositIve & Negative & Ck`trAcy \\
Cut-off & PvmdIëtiva & PrEaIcwiöa & \\
Selóit)titq & Ramvg & Value & \\
Specifici y & & & n
\end{tabular}

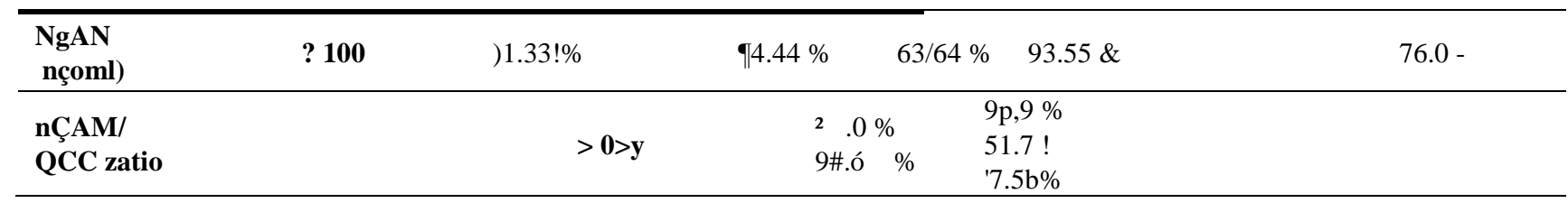

^GIL: neetòophél çelatIneca awsocia|ed lipok`ìin,!NGAH/UBC: åutâopiml çelatif;se !swoãIqted lapocchin/ ubiniry brea4inéne raTio

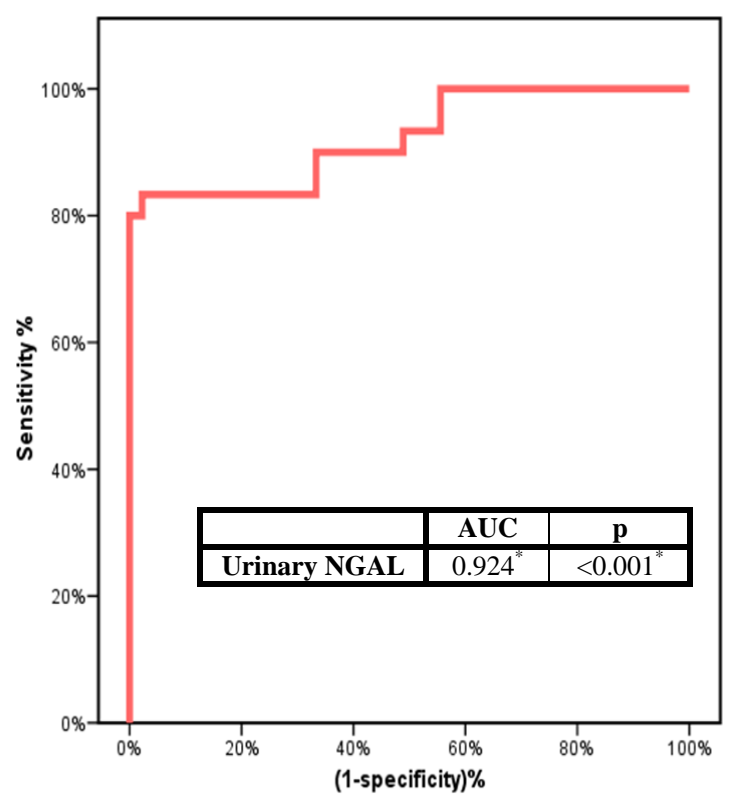

Figure (2): ROC curve for urinary NGAL concentration to diagnose HRS.

\section{DISCUSSION}

Although the most commonly used measure of overall kidney function in clinical practice is serum creatinine

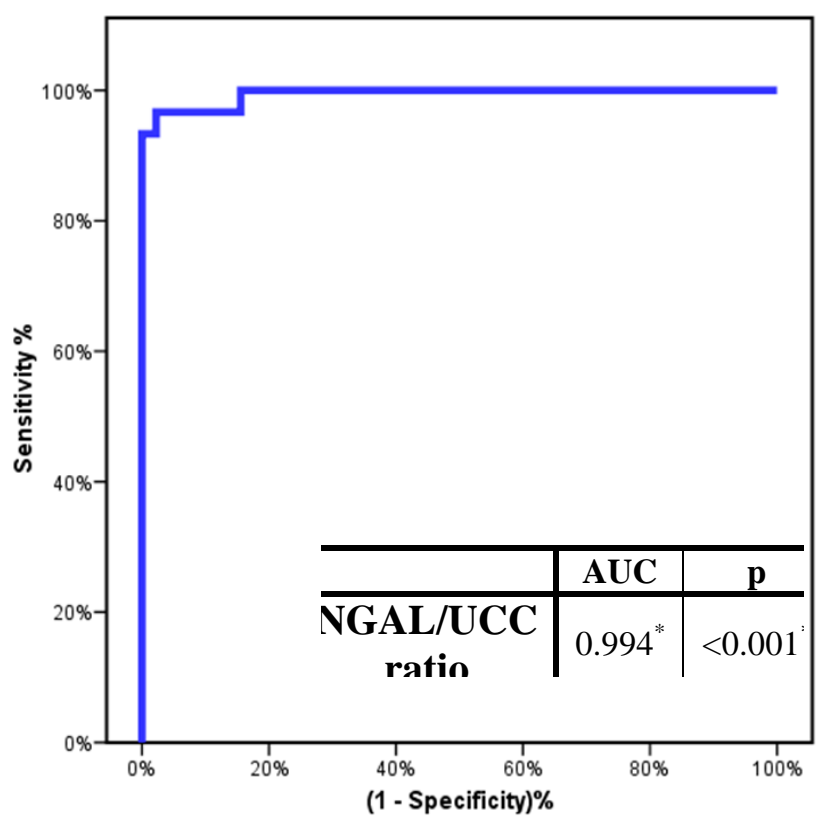

Figure (3): ROC curve for NGAL/UCC ratio to diagnose HRS.

concentration, unfortunately, this measurement is affected by many factors and varies markedly with age, gender and muscle mass. Consequently, many guidelines; including the National Kidney Foundation Dialysis 
Outcome Quality Initiative (K/DOQI) ${ }^{(36)}$, British Renal Association (37) and KDIGO guidelines (38) have recommended the use of prediction equations to estimate the GFR from serum creatinine. The Modification of Diet in Renal Disease (MDRD) ${ }^{(31)}$ formula does not require the use of the patient's weight (making it more suitable for patients with ascites, edema of the body and underweightas well as overweight) and has been shown to be more precise and accurate than the Cockcroft-Gault equation when the GFR is below $60 \mathrm{ml} / \mathrm{min} / 1.73 \mathrm{~m}^{2}$. ${ }^{(39)}$ In addition, the American Diabetes Association (ADA) guidelines for prevention and management of diabetes complications, recommended that the GFR should be estimated using formulae such as the MDRD equation or the CKD-Epidemiology Collaboration (CKD-EPI) equation, which perform better in the presence of microor macroalbuminuria. ${ }^{(40)}$ In fact, CKD-EPI formula showed better correlation with isotope - measured GFR than MDRD formula in Egyptian diabetic patients in a recent study by Abou-Seif et al. ${ }^{(41)}$ Consequently, we chose to use both, the MDRD and the CKD-EPI equations to estimate GFR of all our patients. It is true that the use of serum creatinine concentration to estimate GFR relies on the individual being in steady state, and hence estimated GFR from any prediction equation will be unreliable in the settings of acute renal failure of any cause, however, the practice of using estimating formulas in these situations has been debated and has been used for statistical comparison by other investigators. ${ }^{(42)}$ Our results generally showed lower values of estimated GFR using the extended MDRD (Ext-MDRD) equation than using CKD-EPI formula. Both, however, demonstrated significantly lower values in patients with renal impairment (groups III and IV) compared to other groups and to controls. Nevertheless, the estimated GFR failed to demonstrate a statistically significant difference between group III (HRS) and group IV (CKD), $\mathrm{p}_{6}>0.05$.

Neutrophil gelatinase-associated lipocalin (NGAL) is a relatively novel biomarker that is detectable very early after renal injury. In most clinical scenarios, urinary NGAL is $5-10$ times higher than plasma NGAL after renal injury and may be easier to detect with higher precision. ${ }^{(43)}$ Nevertheless, most authors tended to use the absolute value of urinary NGAL, neglecting the potential differences of osmolality in random urine sample. For that reason, a study by Delanaye et al recommended the use of NGAL ratio rather than the absolute NGAL value, which significantly improved the intra-individual variation observed in NGAL measurements in random urine sample. ${ }^{(44)}$ Our results revealed significantly higher values for urinary NGAL level and NGAL/UCC ratio among all patients with HRS (group III) compared to controls and to other patient groups $(\mathrm{p}<0.001)$. At a cutoff value of $100 \mathrm{ng} / \mathrm{ml}$ for NGAL level, patients with HRS were identified with a sensitivity of $93.33 \%$ and a specificity of $64.44 \%$, while at a cut-off value of 0.9 , urinary NGAL/UCC ratio showed a sensitivity of $60.0 \%$ and a specificity of $93.33 \%$. Moreover, significant correlations of urinary NGAL and NGAL/UCC ratio were found with other parameters of renal function, including serum urea, serum creatinine and estimated GFR by ExtMDRD and CKD-EPI formulas, as well as with Child score. These results were comparable to the finding of Verna et $\mathrm{al}^{(16)}$, who carried out a prospective study on one hundred eighteen patients with and without impaired renal function of different etiologies. They found significant correlations of urinary NGAL with serum creatinine and estimated GFR, and proved that urinary NGAL strongly predicts short-term patient mortality in cirrhotic patients. They also demonstrated that it can differentiate acute kidney injury (AKI) type among cirrhotics, and that patients with HRS have urinary levels NGAL intermediate between those with prerenal azotemia and intrinsic AKI. Also, a study by Zhang et al published in 2015 investigated the effect of NGAL on prognosis of patients with type II HRS, and demonstrated a significant positive correlation of plasma NGAL and urinary NGAL with plasma renin, aldosterone, creatinine, MELD score, Child-Pugh score and grade of ascites. ${ }^{(45)}$ Few Egyptian studies published between 2013 and 2014 by Shawky et al and El-Bassat et al also aimed to assess the usefulness of urinary NGAL as a biomarker for hepatorenal syndrome (HRS) in patients with cirrhosis. ${ }^{(46,47)}$ The results of their studies showed that patients with HRS had significantly higher levels of urinary NGAL compared to those with prerenal azotemia, CKD, or cirrhotic patients with normal kidney function. At a cut-off value of $110 \mathrm{ng} / \mathrm{ml}$, NGAL had sensitivity, specificity, PPV, NPV, and accuracy of $90.2,67.9,79.0,91$, and $88.75 \%$, respectively, to diagnose HRS according to El-Bassat et al. ${ }^{(47)}$ Also, NGAL elevation was more prominent in type I than in type II HRS.

Although serum and urinary NGAL are possibly the most promising emerging biomarkers for early detection of acute kidney injury, its role in CKD, however, is still debatable. Several recent studies have proved serum and urinary NGAL levels as markers of kidney disease severity in CKD. ${ }^{(48-50)}$ A study by Xiang et al has even demonstrated that the concentration of the NGAL increased progressively with the rise in risk categories of CKD. The cut-off value of urinary NGAL was $82.5 \mathrm{ng} / \mathrm{ml}$ for stage 2, and progressively increased to $316.5 \mathrm{ng} / \mathrm{ml}$ for stage 5 CKD. ${ }^{(50)}$ On the other hand, El-Bassat et al ${ }^{(47)}$ found that urinary NGAL levels in cirrhotic patients with CKD were low and equivalent to levels in patients with normal kidney function and prerenal azotemia. ${ }^{(47)}$ In comparison, our work revealed that the difference between urinary NGAL level of group IV (CKD) compared to normal control and to cirrhotic patient groups (I and II) was non-significant ( $\left.\mathrm{p}_{\text {cont }}>0.05\right)$. Nevertheless, when calculating the urinary NGAL/UCC ratio for CKD patients, it proved to be significantly higher than controls ( $\left.p_{\text {cont }}<0.001\right)$ as well as some patients groups $\left(\mathrm{p}_{3}<0.001, \mathrm{p}_{5}<0.001\right)$. In addition, unlike serum urea, creatinine and estimated GER values, both absolute NGAL level and its ratio with urinary creatinine succeeded to differentiate between patients with HRS (group III) and those with established CKD (group IV), with significant difference of mean value between both $\left(\mathrm{p}_{6}<0.001\right)$. 
At this point, however, an important question should be raised about the actual explanation of elevated urinary NGAL level (a marker famous for early diagnosis of intrinsic AKI) in patients with HRS, which is a condition classically considered as being purely functional. ${ }^{(51)} \mathrm{NGAL}$ - on the other hand - is secreted into urine by the thick ascending limb of Henle and collecting ducts of the kidney. Thus, urinary excretion of NGAL is increased in AKI but not in functional renal disease. ${ }^{(52)}$ Our results and the findings of Verna et $a l^{(16)}$ and El-Bassat et $a l ;^{(47)}$ namely detecting kidney injury biomarkers in HRS is hence potentially consistent with recent speculations that HRS may in fact contain some degree of structural injury, likely creating an overlap between HRS and mild intrinsic AKI. Indeed, pathologic investigations have reported subtle kidney tubular and glomerular damage in HRS kidneys, some seen only with electron microscopy. ${ }^{(53,54)}$ Prolonged renal ischemia in late-presenting HRS can also lead to structural damage, such as acute tubular necrosis (ATN), as some data have suggested, ${ }^{(55)}$ thus further blurring the line between structural and functional causes of AKI in cirrhosis. In addition, ATN itself can present clinically with the same features as type -I HRS, thus making the differentiation and decisions on treatment plans even more difficult. ${ }^{(56,57)}$ The traditionally used International Ascites Club (IAC) criteria for diagnosing HRS are useful for their simplicity and applicability at the bedside, but they often lack the data required for distinguishing structural from functional disease. That was why in 2010, a collaboration between the Acute Dialysis Quality Initiative (ADQI) and the IAC, resulted in a proposal for a new term of "Hepatorenal dysfunction", with type II hepatorenal syndrome (HRS) falling within the category of CKD, whilst type I HRS was recognized as a specific diagnosis within the AKI spectrum. ${ }^{(58)}$ It is hence obvious that new, objective tests for accurate distinction between structural from functional AKI in patients with cirrhosis continue to be urgently needed. Multiple biomarkers, including NGAL, interleukin-18 (IL-18), and kidney injury molecule1 (KIM-1) are currently investigated. However, in patients with cirrhosis, where kidney biopsies are uncommonly performed, the very lack of the gold standard against which new tests are to be compared makes the development of new tests challenging.

In light of the above, our study has revealed several limitations. We used the creatinine-based CKD-EPI and Ext- MDRD formulas for estimating GFR in all subjects, including HRS group (who mostly have unsteady serum creatinine), which might have yielded somewhat inaccurate values. However, there is no widely available technique to accurately measure GFR in these patients. This study was also limited by small sample size, especially in the important HRS group. A larger study may have allowed us to evaluate HRS types I and II individually, and also to add other categories for comparison of urinary NGAL like prerenal azotemia or AKI.

\section{REFERENCES}

1. Ruiz-del-Arbol L, Monescillo A, Arocena C, Valer P, Ginès $\mathrm{P}$, Moreira $\mathrm{V}$, et al. Circulatory function and hepatorenal syndrome in cirrhosis. Hepatology 2005; 42:439 - 47.

2. Gines P, Schrier RW. Renal failure in cirrhosis. N Engl J Med 2009; 361:1279-90.

3. Arroyo V, Ginès P, Gerbes A, Dudley F, Gentilini P, Laffi $G$, et al. Definition and diagnostic criteria of refractory ascites and hepatorenal syndrome in cirrhosis. Hepatology 1996; 23:164-76.

4. Gines A, Escorsell A, Gines P, Salo J, Jimenez W, Inglada $\mathrm{L}$, et al. Incidence, predictive factors, and prognosis of the hepatorenal syndrome in cirrhosis with ascites. Gastroenterology 1993; 105:229-36.

5. Gines P, Guevara M, Arroyo V, Rodes J. Hepatorenal syndrome. Lancet 2003; 362:1819-27.

6. Kjeldsen L, Johnsen AH, Sengelv H, Borregaard N. Isolation and primary structure of NGAL, a novel protein associated with human neutrophil gelatinase. J Biol Chem 1993; 268:10425-32.

7. Chan P, Simon-Chazottes D, Mattei MG, Guenet JL, Salier JP. Comparative mapping of lipocalin genes in human and mouse: the four genes for complement $\mathrm{C} 8$ gamma chain, prostaglandin-D-synthase, oncogene-24p3, and progestagen-associated endometrial protein map to HSA9 and MMU2. Genomics 1994; 23:145-50.

8. Cowland JB, Borregaard N. Molecular characterization and pattern of tissue expression of the gene for neutrophil gelatinase-associated lipocalin from human. Genomics 1997; 45:17-23.

9. Friedl A, Stoesz SP, Buckley P, Gould MN. Neutrophil gelatinase-associated lipocalin in normal and neoplastic human tissues. Cell type-specific pattern of expression. Histochem J 1999; 31:433-41.

10. Schmidt-Ott KM, Mori K, Li JY, Kalandadze A, Cohen DJ, Devarajan P, et al. Dual action of neutrophil gelatinaseassociated lipocalin. J Am Soc Nephrol 2007; 18:407-13.

11. Bennett M, Dent CL, Ma Q, Dastrala S, Grenier F, Workman R, et al. Urine NGAL predicts severity of acute kidney injury after cardiac surgery: a prospective study. Clin J Am Soc Nephrol 2008; 3:665-73.

12. Devarajan P. Review: Neutrophil gelatinase-associated lipocalin: a troponin-like biomarker for human acute kidney injury. Nephrology (Carlton) 2010; 15:419-28.

13. Uttenthal LO. NGAL: a marker molecule for the distressed kidney? Clin Lab Internat 2005; 29:39-41.

14. Bolignano D. NGAL levels clearly correlate with severity of renal impairment, probably expressing the degree of active damage underlying the chronic condition. Am J Kidney Dis 2008; 52:595-605.

15. Goldstein SL. Acute kidney injury biomarkers: renal angina and the need for a renal troponin I. BMC Med 2011; 9:135.

16. Verna E, Farrand E, Brown R, Pichardo E, Forster C, Adkins $\mathrm{S}$, et al. Urinary neutrophil gelatinase-associated lipocalin predicts mortality and identifies acute kidney injury in cirrhosis. Dig Dis Sci 2012; 57(9):2362-70.

17. Haase M, Devarajan P, Haase-Fielitz A, Bellomo R, Cruz DN, Wagener G, et al. The outcome of neutrophil gelatinase-associated lipocalin-positive subclinical acute kidney injury: a multicenter pooled analysis of prospective studies. J Am Coll Cardiol 2011; 57:1752-61. 
18. Schuppan D, Afdhal NH. Liver cirrhosis. Lancet 2008; 371(9615):838-51.

19. Tchelepi H, Ralls PW, Radin R, Grant EJ. Sonography of diffuse liver disease. J Ultrasound Med 2002; 21 (9):1023-34.

20. Salerno F, Gerbes A, Ginès P, Wong F, Arroyo V. Diagnosis, prevention and treatment of hepatorenal syndrome in cirrhosis. Gut 2007; 56: 1310-8.

21. Volk M L, Marrero JA. Advances in critical care hepatology. Miverva Anestesiol 2006; 72(5): 269-81.

22. Fluckinger M, Haas H, Merschak P, Glasgow BJ, Redl B. Human tear lipocalin exhibits antimicrobial activity by scavenging microbial siderophores. Antimicrob Agents Chemother 2004; 48: 3367-72.

23. Goetz DH, Holmes MA, Borregaard N, Bluhm ME, Raymond KN, Strong RK. The neutrophil lipocalin NGAL is a bacteriostatic agent that interferes with siderophore mediated iron acquisition. Mol Cell 2002; 10:1033-43.

24. Schmidt-Ott KM, Mori K, Li JY, Kalandadze A, Cohen DJ, Devarajan P, et al. Dual action of neutrophil gelatinase-associated lipocalin. J Am Soc Nephrol 2007; 18(2): 407-13.

25. Pugh RN, Murray-Lyon IM, Dawson JL, Pietroni MC, Williams R. Transection of the oesophagus for bleeding oesophageal varices. Br J Surg 1973; 60(8):646-9.

26. van Dam GM, Gips CH, Reisman Y, Maas KW, Purmer IM, Huizenga JR, et al. Major clinical events, signs and severity assessment scores related to actual survival in patients who died from primary biliary cirrhosis: a longterm historical cohort study. Hepatogastroenterology 1999; 46: 108--15.

27. Hricak H, Cruz C, Romanski R, Uniewski MH, Levin NW, Madrazo BL. Renal parenchymal disease: sonographic- histologic correlation. Radiology 1982; 144:141-7.

28. Roberts LW, MC Millin GA, Burtis CA, Bruns DE. Reference information for the clinical laboratory. In: Burtis CA, Ashwood ER, Bruns DE (eds). Tietz textbook of clinical chemistry and molecular diagnostics. $4^{\text {th }}$ ed. St Louis: Elsevier Saunders; 2006. 2251-318.

29. Nicoll D, Lu CM, McPhee SJ, Pignone M. Complete blood cell count. In: Nicoll D, Stephen J, Stephen M, Michael P, Chuanyi M, Chuanyi L, et al (eds). Pocket guide to diagnostic tests. 5thed. New York: McGrawHill Companies, Inc; 2008. 84-172.

30. Levey AS, Stevens LA, Schmid CH, Zhang YL, Castro AF 3rd, Feldman HI, et al. A new equation to estimate glomerular filtration rate. Ann Intern Med 2009; 150(9):604-12.

31. Levey AS, Bosch JP, Lewis JB, Greene T, Rogers N, Roth D. A more accurate method to estimate glomerular filtration rate from serum creatinine: a new prediction equation. Modification of Diet in Renal Disease Study Group. Ann Intern Med 1999; 130:461-70.

32. KDIGO CKD Work Group. KDIGO 2012 clinical practice guideline for the evaluation and management of chronic kidney disease. Kidney Int Suppl 2013; 3: 1-150.

33. Lippi G, Aloe R, Storelli A, Cervellin G, Trenti T. Evaluation of NGAL Test ${ }^{\mathrm{TM}}$, a fully-automated neutrophil gelatinase-associated lipocalin (NGAL) immunoassay on Beckman Coulter AU 5822. Clin Chem Lab Med 2012; 50:1581-4.
34. Kotz S, Balakrishnan N, Read CB, Vidakovic B. Encyclopedia of statistical sciences. 2nd ed. Hoboken, N.J.: Wiley-Interscience; 2006.

35. Kirkpatrick LA, Feeney BC. A simple guide to IBM SPSS statistics for version 20.0. Student ed. Belmont, Calif.: Wadsworth, Cengage Learning; 2013.

36. Kirkpatrick LA, Feeney BC. A simple guide to IBM SPSS statistics for version 20.0. Student ed. Belmont, Calif.: Wadsworth, Cengage Learning; 2013. K/DOQI clinical practice guidelines for chronic kidney disease: evaluation, classification, and stratification. Am J Kidney Dis 2002; 39:S1-266.

37. Burden R, Tomson C; Guideline Development Committee, Joint Specialty Committee on Renal Disease of the Royal College of Physicians of London and the Renal Association. Identification, management and referral of adults with chronic kidney disease: concise guidelines. Clin Med 2005; 5(6):635-42.

38. Eknoyan G, Lameire N, Barsoum R, Eckardt KU, Levin $\mathrm{A}$, Levin $\mathrm{N}$, et al. The burden of kidney disease: improving global outcomes. Kidney Int 2004; 66:1310-4.

39. Johnson DW. Use of estimated glomerular filtration rate to assess level of kidney function. Nephrology 2005; 10:S140-6.

40. Vucic Lovrencic M, Radisic Biljak V, Bozicevic S, Prasek M, Pavkovic P, Knotek M. Estimating glomerular filtration rate (GFR) in diabetes: the performance of MDRD and CKD-EPI equations in patients with various degrees of albuminuria. Clin Biochem 2012; 45(18):1694-6.

41. Abou-Seif K, Makkeyah Y, Behairy M, Ali MM. Performance of CKD-EPI versus MDRD among Diabetic Egyptians. Life Sci J 2014; 11(10): 1284-90.

42. Bragadottir G, Redfors B, Ricksten SE. Assessing glomerular filtration rate (GFR) in critically ill patients with acute kidney injury--true GFR versus urinary creatinine clearance and estimating equations. Crit Care 2013; 17(3):R108.

43. Jeong TD, Kim S, Lee W, Song GW, Kim YK, Chun S, et al. Neutrophil gelatinase-associated lipocalin as an early biomarker of acute kidney injury in liver transplantation. Clin Transplant 2012; 26(5):775-81.

44. Delanaye P, Rozet E, Krzesinski JM, Cavalier E. Urinary NGAL measurement: biological variation and ratio to creatinine. Clin Chim Acta 2011; 412(3-4):390.

45. Zhang ZC, Wu LL, Chen X, Chen LL, Wang GP, Yan HF. Effect of neutrophil gelatinase-associated lipocalin on prognosis of patients with type 2 hepatorenal syndrome. Zhonghua Gan Zang Bing Za Zhi 2015; 23(6):449-53.

46. Shawky JA, Khorshed SE, Labib HA. Urinary neutrophil gelatinase-associated lipocalin as predictor for development of hepatorenal syndrome in patients with hepatic cirrhosis Afro-Egypt. J Infect Endem Dis 2014; 4(3): 143-8.

47. El-Bassat H, Ziada DH, Taha A, Alm-Eldin R. Urinary neutrophil gelatinase-associated lipocalin as a biomarker for the diagnosis of hepatorenal syndrome in cirrhotic patients. Tanta Med J 2013; 41:346-52.

48. Bolignano D, Lacquaniti A, Coppolino G, Donato V, Campo S, Fazio MR, et al. Neutrophil gelatinaseassociated lipocalin (NGAL) and progression of chronic kidney disease. Clin J Am Soc Nephrol 2009; 4(2):337-44. 
49. Shen SJ, Hu ZX, Li QH, Wang SM, Song CJ, Wu DD, et al. Implications of the changes in serum neutrophil gelatinase-associated lipocalin and cystatin $\mathrm{C}$ in patients with chronic kidney disease. Nephrology (Carlton) 2014; 19(3):129-35.

50. Xiang D, Zhang H, Bai J, Ma J, Li M, Gao J, et al. Clinical application of neutrophil gelatinase-associated lipocalin in the revised chronic kidney disease classification. Int J Clin Exp Pathol 2014; 7(10):7172-81.

51. Iwatsuki S, Popovtzer MM, Cormal JL, Ishikawa M, Putnam CW, Katz FH, et al. Recovery from hepatorenal syndrome after orthotopic liver transplantation. N Engl J Med 1973; 289:1155-9.

52. McDonald FD, Brennan LA, Turcotte JG. Sever hypertension and elevated plasma renin activity following transplantation of hepatorenal donor kidney into a nephric recipients. Am J Med 1973; 54:39-43.
53. Mandal AK, Landing M, Fahmy A. Acute tubular necrosis in hepatorenal syndrome: an electron microscopy study. Am J Kidney Dis 1982; 2:363-74.

54. Kanel GC, Peters RL. Glomerular tubular reflux - a morphologic renal lesion associated with hepatorenal syndrome. Hepatology 1984; 4:242-6.

55. Francoz C, Glotz D, Moreau R, Durand F. The evaluation of renal function and disease in patients with cirrhosis. J Hepatol 2010; 52(4):605-13.

56. Meyrier A, Hill GS, Simon P. Ischemic renal diseases: new insights into old entities. Kidney Int 1998; 54:2-13.

57. Moreau R, Lebrec D. Diagnosis and treatment of acute renal failure in patients with cirrhosis. Best Pract Res Clin Gastroenterol 2007; 21:111-23.

58. Wong F, Nadim MK, Kellum JA, Salerno F, Bellomo $\mathrm{R}$, Gerbes A, et al. Working party proposal for a revised classification system of renal dysfunction in patients with cirrhosis. Gut 2011; 60: 702-9. 